\title{
The Effects of He-Ne Laser and Enhanced Ultraviolet-B Radiation on Proliferating-Cell Nuclear Antigen in Wheat Seedlings
}

\author{
Feifeng Liu ${ }^{1,2}$, Huize Chen ${ }^{1,2}$, Rong Han 1,2* \\ ${ }^{1}$ College of Life Science, Shanxi Normal University, Linfen, China \\ ${ }^{2}$ Higher Education Key Laboratory of Plant Molecular and Environmental Stress Response \\ (Shanxi Normal University) in Shanxi Province, Linfen, China \\ Email: $\underline{\text { hhwrsl@163.com }}$
}

Received 30 April 2015; accepted 22 May 2015; published 25 May 2015

Copyright (C) 2015 by authors and Scientific Research Publishing Inc.

This work is licensed under the Creative Commons Attribution International License (CC BY). http://creativecommons.org/licenses/by/4.0/

(c) (i) Open Access

\section{Abstract}

The level of ultraviolet-B (UV-B) radiation on the Earth's surface has increased due to depletion of the ozone layer. Here, we explored the effects of continuous wave He-Ne laser irradiation (632 $\mathrm{nm}$, $5 \mathrm{~mW} \cdot \mathrm{mm}^{-2}, 2 \mathrm{~min} \cdot \mathrm{d}^{-1}$ ) on proliferating-cell nuclear antigen (PCNA) damage repair function of wheat seedlings exposed to enhanced UV-B radiation $\left(10.08 \mathrm{~kJ} \cdot \mathrm{m}^{-2} \cdot \mathrm{d}^{-1}\right)$ at the early growth stages. Wheat seedlings were irradiated with enhanced UV-B, He-Ne laser treatment or a combination of the two. We explored the transcripts of PCNA in each treatment group using RT-PCR. In addition, total proteins were extracted from the 7-day-old wheat leaves, analyzed by SDS-PAGE and identified by western blot. The results showed that the transcription of PCNA was weakened following UV-B radiation compared to the control. However, when seedlings were subjected to elevated UV-B-damaging radiation followed by He-Ne laser irradiation, the expression of PCNA was significantly higher than UV-B radiation alone. These results suggest that He-Ne laser has an active role in repairing the UV-B damaging effects. In order to further investigate the function of PCNA, dynamic arrangements of PCNA in wheat root-tip cells were observed with confocal laser scanning microscopy (CLSM). The PCNA was marked fluorescent dimming and strength weakened in enhanced UV-B radiation (UV-B) compared with the control group (CK) during processing. It shows that PCNA may be involved in the separation of chromosomes.

\section{Keywords}

Wheat, PCNA, UVB Radiation, He-Ne Laser, CLSM

\footnotetext{
*Corresponding author.

How to cite this paper: Liu, F.F., Chen, H.Z and Han, R. (2015) The Effects of He-Ne Laser and Enhanced Ultraviolet-B Radiation on Proliferating-Cell Nuclear Antigen in Wheat Seedlings. American Journal of Plant Sciences, 6, 1206-1214. 


\section{Introduction}

Plants as sessile organisms that require sunlight to grow and develop, are inevitably exposed to ultraviolet (UV) wavelengths (200 - $400 \mathrm{~nm}$ ), which represent almost $7 \%$ of the electromagnetic radiation emitted from the sun [1]. Sunlight contains energy rich UV-A (320 - $400 \mathrm{~nm})$, UV-B (290 - $320 \mathrm{~nm})$, and UV-C (280 - $100 \mathrm{~nm})$ light. UV-B light (280 - $315 \mathrm{~nm}$ ) is a natural component of sunlight, and, due to its short wavelength, it has the highest energy of the sunlight spectrum at the Earth's surface [2]. Low fluence UV-B light promotes photomorphogenesis, and induces the transcription of genes involved in flavonoid synthesis [3]. While high-intensity UV-B light causes damage to DNA, protein, and other macromolecules [2]. GISS modelling has suggested that there is a springtime enhancement of erythemal UV doses of up to $14 \%$ in the Northern Hemisphere and $40 \%$ in the Southern Hemisphere. Even a small increase in incident UV-B radiation can have significant biological effects [4]. Hence, it is important to study how crops protect themselves against the potentially damaging effects of UV-B.

Compared with chemical methods for plant UV-B protection, physical methods are more effective and beneficial. Low dose of laser irradiation can promote plant growth and development, physiological metabolism [5]. Treatment with He-Ne laser helps accelerate seedling growth and development [6], and can repair UV-B-induced damage and shorten the recovery time [7] [8] He-Ne laser can repair damage induced by osmotic stress in wheat [9].

PCNA was originally identified in humans as an antigen in patients with systemic lupus erythaematosus and as a protein that was synthesized during the S-phase of the cell cycle. The presence of the protein in the nucleus of dividing cells led to the name PCNA. Subsequent studies demonstrated that genes that encode PCNA are present in all eukarya and that the proteins are essential for cell viability [10]. DNA metabolism is mediated by protein complexes that consist of various DNA-processing proteins. The DNA sliding-clamp family consists of $\beta$-clamps in bacteria and PCNA in eukaryote and archaea [11]. The PCNA is a key component of the eukaryotic DNA replication machinery. It forms a pseudo-6-fold symmetry ring around DNA and acts as a DNA polymerase $\delta$ processivity factor [12]. In addition to replicative DNA polymerases, PCNA and its homologues have been shown to interact with a broad range of DNA modifying enzymes implicated in such DNA metabolic processes as DNA replication, Okazaki fragment maturation, DNA methylation, nucleotide excision repair (NER), mismatch repair (MMR) and long-patch base excision repair (LP-BER) [13]. The gene sequences coding for PCNA have been identified and reported for diverse species, including human [14], mouse [15], yeast [16], rice [17], common bean [18] and runner bean [19]. Moreover, in some of them, for instance Drosophila [20] [21], Arabidopsis [22] and maize [23] [24] two pcna genes were discovered. The PCNA is a conserved protein encoded in the genomes of archaebacteria and eukaryotic organisms [12].

Preliminary work of our group found that enhanced UV-B could inhibit the cell mitosis frequency of wheat and cause chromosome aberration. The phenomenon of "partition-bundle division" is one of the distortion types. "Partition-bundle division" is also called multiple bundle division. It was found that during the anaphase to telophase of mitosis, chromosomes of the wheat root tip cells fell into "three bundles", "four bundles", "six bundles" after the UV-B radiation [25]. They are generally distributed at the two poles, but the chromosome bundles at the two poles may be different and the number of chromosomes on the same bundle is not entirely equal. In addition, cell wall is not formed between bundles, and thus leads to multiple bundles [5]. In order to clarify this phenomenon, our group has been using wheat as research materials and studying the effects of He-Ne laser irradiation and enhanced UV-B radiation on wheat from various aspects involved in changes in morphology, physiology, chromosome and cytoskeleton. Here, we investigate the roles of wheat PCNA in tolerance of UV-B induced DNA damage. Chromosomes are made up of DNA and proteins. Therefore, PCNA may affect chromosome aberration.

\section{Materials and Methods}

\subsection{Plant Materials}

"ML7113" (Triticum aestivum) was supplied by wheat Research Institute of Shanxi Academy of Agricultural Sciences. The wheat seeds of fully germination and uniform size were selected, sterilized for 10 min with $1 \%$ $\mathrm{NaClO}$, and then washed for 10 min with running water, and then cultured in Petri dishes with 30 seeds per dish, and each group of repeated three times at $25^{\circ} \mathrm{C}$ and $60 \%$ relative humidity under a $8 \mathrm{~h} / 16 \mathrm{~h}$ light/dark regime for 7 days. The materials were divided into four groups: control group(CK), UV-B radiation group (B), He-Ne laser 
irradiation group (L), compound treated group with UV-B radiation and He-Ne laser irradiation (BL). (The detailed methods were showed in Table 1 ).

\subsection{UV-B Radiation Treatment}

Enhanced UV-B radiation was provided by filtered Qin brand (Baoji Lamp Factory, China).The lamps were suspended above and perpendicular to the pots. The power intensity of UV-B radiation was $10.08 \mathrm{~kJ} \cdot \mathrm{m}^{-2} \cdot \mathrm{d}^{-1}$ treatment germination of wheat, every day deal with $8 \mathrm{~h}$, a total of $7 \mathrm{~d}$ processing.

\subsection{He-Ne Laser Irradiation}

High-power laser irradiation apparatus (Nanjing Laser Instrument; wavelength: $633 \mathrm{~nm}$; power intensity: 5 $\mathrm{mW} \cdot \mathrm{mm}^{-2}$; beam diameter: $1.5 \mathrm{~mm}$ ) were used for materials treatment. The wheat seedlings were exposed to He-Ne laser irradiation for 7 days with 2 min each day in the dark, to prevent the influence of stray lights.

\subsection{Semi-Quantitative RT-PCR}

Total RNA was extracted from approximately 100 mg of fresh wheat leaves with RNAiso Plus reagent (TaKaRa) according to the manufacturer's instructions. Then, First-strand complementary cDNA was synthesized by reverse transcription of $5 \mu \mathrm{g}$ total RNA using Prime Script RT-PCR Kit (TaKaRa) The following primers used in Semi-quantitative RT-PCR were PCNA1-F: 5'-TCGTGAGGATGCCTTCCAAT-3';

PCNA1-R: 5'-TTGCATCTTCCGGCTTGTCT-3'; PCNA2-F: 5'-ATGTCGCGTTGGTGTCTCTT-3';

PCNA2-R: 5'-AGTGTCGCTACCATCATCAGC-3; From cDNA to DNA Amplification conditions were carried out under the following conditions: 1 min of denaturation at $94^{\circ} \mathrm{C}$; 35 cycles at $94^{\circ} \mathrm{C}$ for $30 \mathrm{~s}, 56.5^{\circ} \mathrm{C}$ for $30 \mathrm{~s}$, and $72^{\circ} \mathrm{C}$ for $30 \mathrm{~s}$; followed by a $10 \mathrm{~min}$ extension at $72^{\circ} \mathrm{C}$. Amplified PCR products were separated on a $1 \%$ agarose gel containing $1.5 \%(\mathrm{w} / \mathrm{v})$ ethidium bromide and visualized by a GIS Gelatum imaging system (Tanon, Shanghai, China). GAPDH was compared as a compared gene transcription:

GAPDH-F: 5-T GGTTGATCTCGTTGTGCAGGTCTC-3';

GAPDH-F: 5'-GTCAGCCAAGTCAACAACTCTCTG-3'.

\subsection{The extraction of Total Protein}

$250 \mathrm{mg}$ of the 7-day-old fresh wheat leaves of each group were taken and then were dissected with clean tools on ice and as quickly as possible to prevent degradation by proteases. Then we placed the tissue in eppendorf tubes and immersed the tubes in liquid nitrogen to snap freeze and kept samples on ice for immediate homogenization. $2000 \mu \mathrm{l}$ lysis buffer ( $0.5 \mathrm{mM}$ Calcium chloride, 0.5\% NP-40, $0.5 \mathrm{mM} \beta$-Mercaptoethanol, $50 \mathrm{Mm}$ Tris$\mathrm{Hcl} \mathrm{pH}$ 8.0, $0.2 \mu \mathrm{g} / \mathrm{L}$ Aprotinin and $1 \mathrm{mmol} / \mathrm{LPMSF}$ ) were rapidly added into the tubes, and made the samples centrifuged for $20 \mathrm{~min}$ at $12,000 \mathrm{rpm}$ at $4^{\circ} \mathrm{C}$ in a micro centrifuge. Next, we removed the tubes from centrifuge and transferred the supernatant into fresh tubes. The supernatant was total protein samples. The last, total protein samples and the sample buffer (20\% glycerol, 10\% SDS, $10 \% \beta$-Mercaptoethano, $150 \mathrm{mM}$ Tris-Hcl) were mixed according to the proportion $1: 1$. Next the mixture in a boiling water bath for five minutes, after, the mixture cools, can be used for the Western blotting.

\subsection{Analysis of the Protein Electrophoresis and Western Blot}

To determine protein level changes that we performed western blot analysis. Samples with same amount of pro-

Table 1. Establishment and procedure of different treatment.

\begin{tabular}{ccccc}
\hline Treatment & Light & Enhanced UV-B radiation & He-Ne laser irradiation & Dark culture \\
\hline CK & $8 \mathrm{~h} / \mathrm{d}$ & - & - & $16 \mathrm{~h} / \mathrm{d}$ \\
B & $8 \mathrm{~h} / \mathrm{d}$ & $8 \mathrm{~h} / \mathrm{d}$ & - & $16 \mathrm{~h} / \mathrm{d}$ \\
L & $8 \mathrm{~h} / \mathrm{d}$ & - & $2 \mathrm{~min} / \mathrm{d}$ & $16 \mathrm{~h} / \mathrm{d}$ \\
BL & $8 \mathrm{~h} / \mathrm{d}$ & $8 \mathrm{~h} / \mathrm{d}$ & $2 \mathrm{~min} / \mathrm{d}$ & $16 \mathrm{~h} / \mathrm{d}$ \\
\hline
\end{tabular}

Annotations: Light/dark period of irradiation treatments. CK: control group; B: enhanced UV-B radiation alone; L: laser treatment; BL: combined UV-B and He-Ne radiation. 
teins for Western blotting were separated on $12 \%$ sodium dodecyl sulfate-polyacrylamide gel electrophoresis (SDS-PAGE) and transferred onto a polyvinylidene difluoride (PVDF) membrane. The membrane was incubated at room temperature in blocking solution with 5\% bovine serum albumin (BSA) for $2 \mathrm{~h}$ in phosphatebuffered saline (PBS,137mM Sodium chloride, $2.68 \mathrm{mM}$ Potassium chloride, $8.04 \mathrm{mM}$ Disodium hydrogen phosphate and $1.47 \mathrm{mM}$ Potassium dihydrogen phosphate) containing $0.05 \%$ Tween-20. Afterwards, they were incubated with monoclonal mouse-anti-PCNA antibody (Abcam) attenuation 400-fold with TBST containing 1\% Tween-20 and 3\% BSA at $4{ }^{\circ} \mathrm{C}$ overnight after washed three times in TBST. Then the membrane was incubated with horseradish peroxidase conjugated anti-mouse IgG at room temperature for $2 \mathrm{~h}$. Then, the Membrane was washed three times in TBST. Finally positive signals were visualized using eECL Western Blot Kit (CWBIO).

\subsection{Determination Method of the Contents of PCNA Proteins and Statistical Analysis}

Quantity One can determination the contents of PCNA proteins. Then, SPSS software Analysis of the samples that arranged in completely randomized designs with four repeating groups. Statistical significance and ANOVA values are from four duplicate values. The last, origin software was used four repeating groups building a bar chart.

\subsection{Analysis of the Immunolabelling}

Root tips of wheat were fixed with paraformaldehyde for $1 \mathrm{~h}$, and cellulase and pectinase were used for enzymolysis to take out the cell wall for $2 \mathrm{~h}$. Then, the root tip were used polyglutamic acid was fixed for the root tip did not move. Following, Then the root tip cells were incubated at $4^{\circ} \mathrm{C}$ overnight with monoclonal mouse-antiPCNA antibody (abcam) attenuation 300-fold with PBS containing 3\% Tritonx-100, 5\% DMSO and 2\% BSA at $4^{\circ} \mathrm{C}$ overnight. The FITC-conjugated goat anti-mouse IgG was used as secondary antibody (green) diluted 200-fold with PBS. 4, 6-diamidino-2-phenylindole dihydrochloride (DAPI) was used to stain the cell nuclei (blue) at a concentration diluted 700-fold. Then, observed root-tip cells by confocal laser scanning microscopy (CLSM).

\section{Results}

\subsection{Semi-Quantitative RT-PCR Detection and Analysis of PCAN1 and PCNA2 Expression in Wheat Leaves}

Specific primers against PCNA1 and PCNA2 respectively were carried out Semi-quantitative RT-PCR experiments. The PCR products the DNA were separated by electrophoresis on $1 \%$ agarose gels containing ethidium bromide $1.5 \%(\mathrm{w} / \mathrm{v})$ to confirm its magnitude and verify the presence of a unique PCR product. The mRNA expression levels of each gene were measured using GAPDH as a reference (Figure 1(a) and Figure 1(b))

\subsection{Total Expression of PCNA1 and PCNA2 in Wheat Leaves}

Transcriptase (RT)-PCR product of PCNA1 and PCNA2 bands were analyzed. By densitometry using Quantity One 1-D gel image analysis softwar (Bio-Rad, Hercules, CA, United States). (Figure 2(a) and Figure 2(b)) shows the different processing change of the content in the transcripts of PCNA. By Figure 2(a) know that enhanced UV-B radiation (B) caused a recede by $19 \%$ in the transcripts of PCNA1 compared with the control group (CK). When wheat seedlings were subjected to elevated UV-B-damaging radiation followed by He-Ne laser irradiation (BL), the express of PCNA1 were enhance by $9 \%$ compared with UV-B radiation alone, but was not significantly different from the control group. However, by He-Ne laser irradiation (L) Significantly different and enhance by $17 \%$ compared with the control group (CK). It can thus be seen, in different treatment in the transcripts of PCNA content form high to low were L $>$ CK $>$ BL $>$ B. By Figure 2(b) know that enhanced UV-B radiation (B) caused a recede by $25 \%$ in the transcripts of PCNA2 compared with the control group (CK). when wheat seedlings were subjected to elevated UV-B-damaging radiation followed by He-Ne laser irradiation(BL), the expression of PCNA1 were enhance by $10 \%$ compared with UV-B radiation alone. By He-Ne laser irradiation (L) Significantly different and enhance by $19 \%$ compared with the control group (CK). by the above results can speculated that PCNA2 than PCNA1 for UV-B and He-Ne laser more sensitive, also, the UV-B radiation interfere with normal metabolism of nucleinic acid, He-Ne laser irradiation to remission the effects of enhanced 


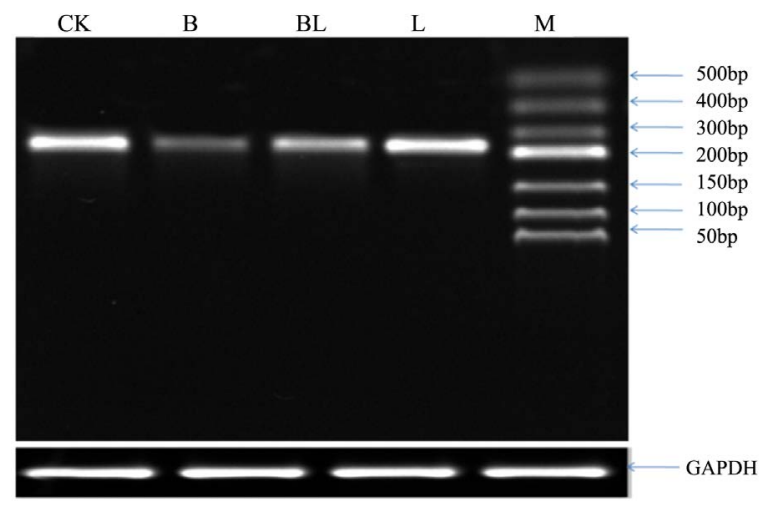

(a)

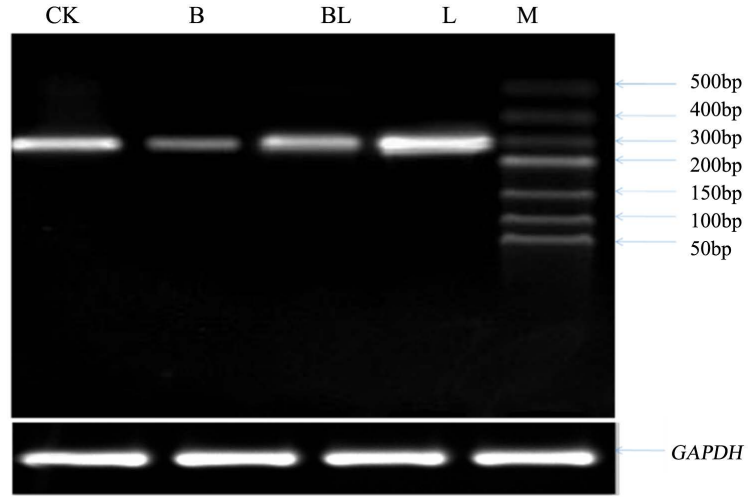

(b)

Figure 1. (a) The agarose electrophoresis of PCNA1 with RT-PCR from wheat leaves. CK: control group; B: enhanced UV-B radiation alone; L: laser treatment; BL: combined UV-B and He-Ne radiation M: mark, Different bands represent different values. GAPDH: as a reference; (b) The agarose electrophoresis of PCNA2 with RT-PCR from wheat leaves. CK: control group; B: enhanced UV-B radiation alone; L: laser treatment; BL: combined UV-B and He-Ne radiation, M: mark, Different bands represent different values. GAPDH: as a reference.

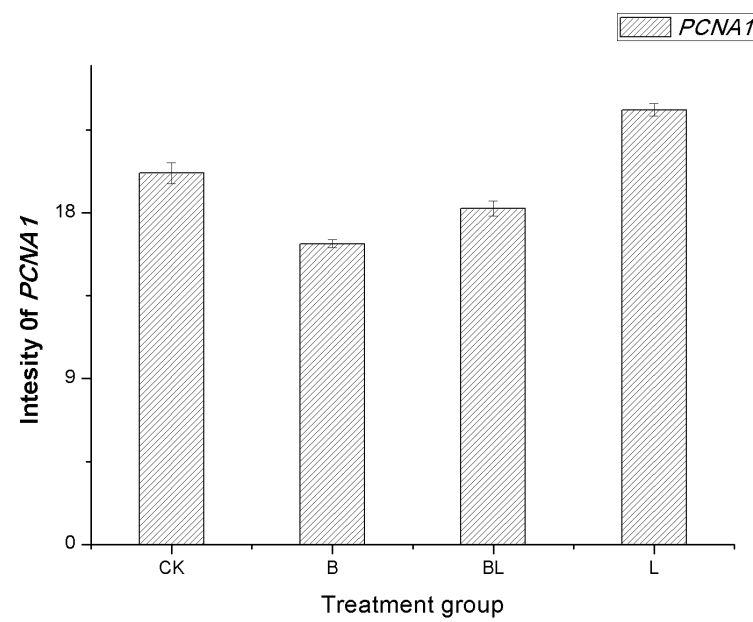

(a)

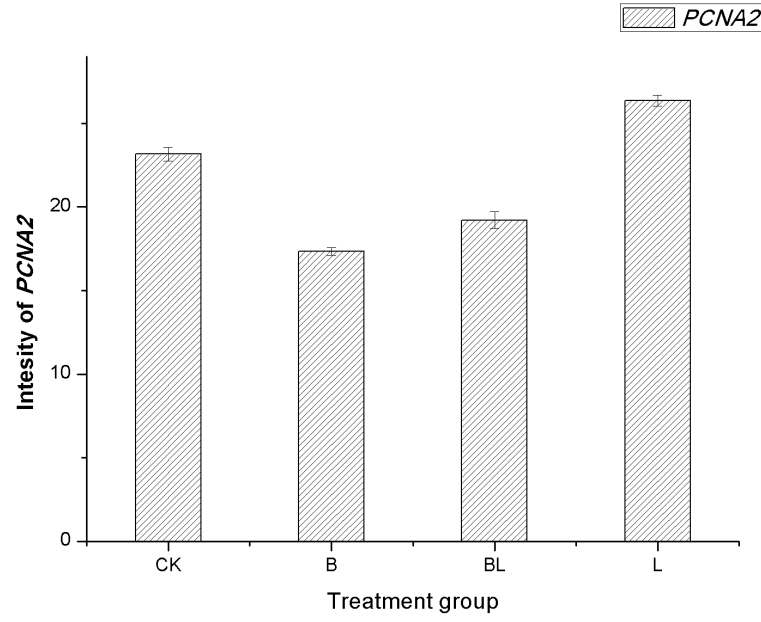

(b)

Figure 2. (a) The gradation analysis the content in the transcripts levels of PCNA1 in wheat leave. CK: control group; B: enhanced UV-B radiation alone; L: laser treatment; BL: combined UV-B and He-Ne radiation. Vertical axis represents different groups gene expression changed in wheat Seedlings; (b) The gradation analysis the content in the transcripts levels of PCNA2 in wheat leave CK: control group; B: enhanced UV-B radiation alone; L: laser treatment; BL: combined UV-B and He-Ne radiation. Vertical axis represents Different groups gene expression changed in wheat seedlings.

UV-B radiation on nucleinic acid metabolism of wheat.

\subsection{Analysis and Identification of PCNA Total Proteins in Wheat Leaves by Western Blot}

At first, total proteins in wheat leaves with same amount of different groups for Western blotting were separated on $12 \%$ sodium dodecyl sulfate-polyacrylamide gel electrophoresis (SDS-PAGE). Proliferating cell nuclear antigen (PCNA) is a key component of the DNA replication machinery present in the nuclei of all dividing cells in eukaryotes. (RAD5a ubiquitin ligase is involved in ubiquitination of Arabidopsis thaliana proliferating cell nuclear antigen) Molecular weight is about $30 \mathrm{KD}$. Between $20.1 \mathrm{KD}$ and $31 \mathrm{KD}$ can clearly get a main band (Figure 3(a)). As indicated by the arrows, main bands were analyzed by densitometry using Quantity One 1-D gel image analysis software (BioRad, Hercules, CA, United States).which laid the foundation for identification of PCNA proteins using western blot in the next step. To further confirm the existence of PCNA in wheat leaves, then incision the PCNA main band used for Western Blot and transferred onto a polyvinylidene difluoride 
(PVDF) membrane for determine the target protein. By western blot analysis shows Wheat total protein PCNA in the immune response, and only now single hybridization band with the $30 \mathrm{KD}$ (Figure 3(b)). This demonstrates the existence of PCNA in wheat leaves.

\subsection{Determination of the Contents of PCNA in Wheat Leaves}

The contents of PCNA proteins were shown in (Figure 4). Different treatment groups in wheat seedlings protein have obvious difference. Compared with the control group (CK), the protein content of PCNA in the wheat leaves were receded by $44.3 \%$, the extremely significant difference $(\mathrm{P}<0.01)$, in enhanced UV-B radiation treatment group that it can inhibit the synthesis of protein. In the single He-Ne laser irradiation treatment group (L), leaves protein content was increased by $16.8 \%(0.01<\mathrm{P}<0.05)$ relative to the control more significant. When wheat seedlings were subjected to elevated UV-B-damaging radiation followed by He-Ne laser irradiation (BL), Compared with the single enhanced UV-B radiation treatment group, the content of PCNA in the elevated UV-B-damaging radiation followed by He-Ne laser irradiation $(\mathrm{BL})$ increased by $14.2 \%(\mathrm{P}<0.05)$ and the difference was significant. Therefore enhanced UV-B radiation prompted PCNA protein inhibition in wheat nucleus. When laser treatment speculated that may be associated with the resistance of plants.

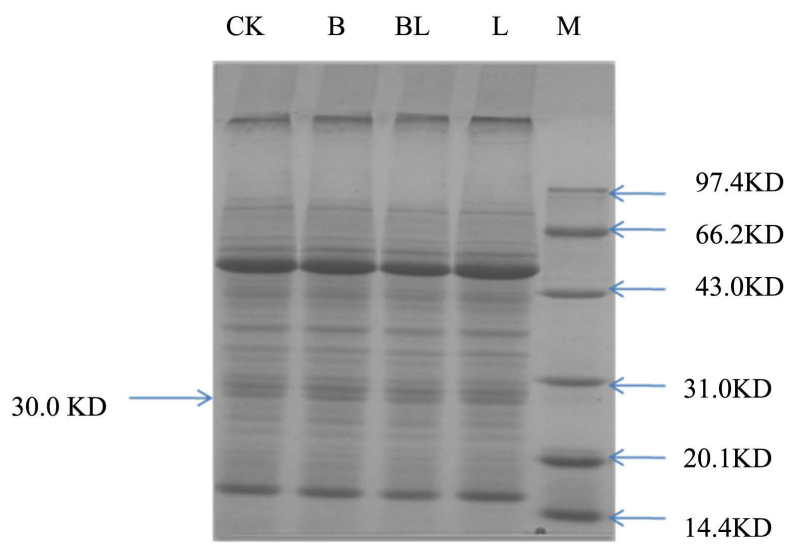

(a)

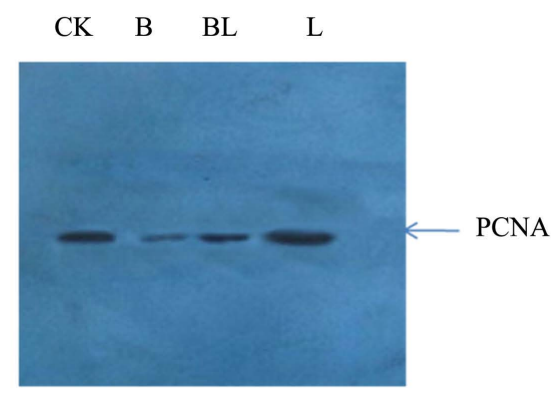

(b)

Figure 3. (a) (b) The SDS-PAGE electrophoresis of total proteins in wheat leaves and Western blot analysis of PCNA in wheat leaves of different groups. CK: control group; (B) enhanced UV-B radiation alone; L: laser treatment; BL: combined UV-B and He-Ne radiation. M: mark; different bands represent different protein values.

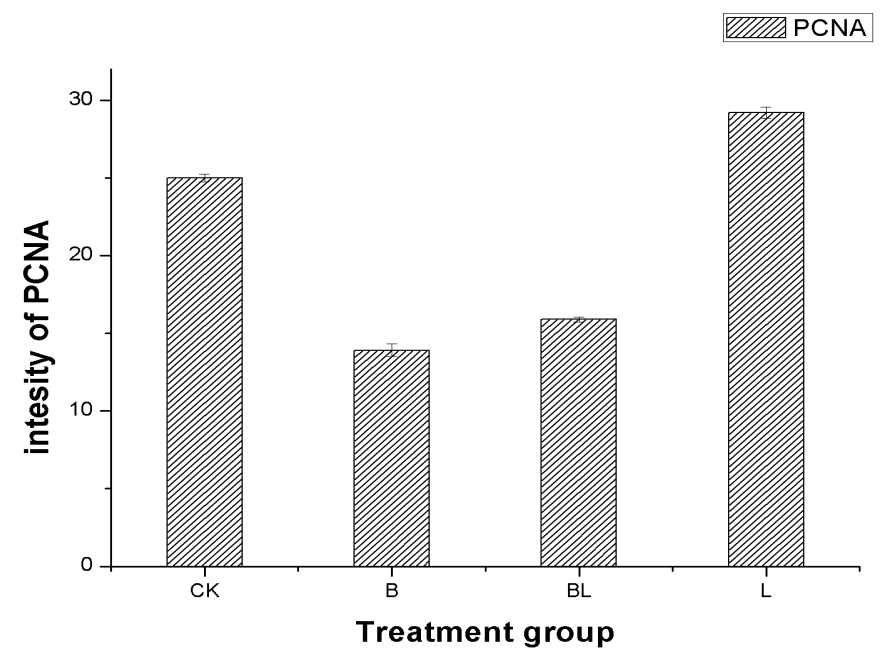

Figure 4. PCNAs protein was gradation analysis. CK: control group; B: enhanced UV-B radiation alone; L: laser treatment; BL: combined UV-B and He-Ne radiation. Vertical axis represents different groups protein changed in wheat seedlings. 


\subsection{Subcellular Localization of PCNA Proteins at the Stage of Division under UV-B Condition}

The presence of the PCNA protein in the nucleus of dividing cells and synthesized during the S-phase of the cell cycle. PCNA play mainly role in S-phase, then in M-phase content gradually reduce of mitosis. But, PCNA still affect M-phase separation of chromosome in mitosis. To study the role of PCNA in mitosis, we examined by confocal laser Scanning microscopy the subcellular localization of PCNAs proteins at the stage of division. In this figure, chromatin and PCNAs are shown as blue and green respectively. From the figure we can see the distribution of PCNAs clearly during the cell mitosis. (Addition) We observed mitosis occurs abnormal and chromosome aberration. The PCNAs was marked fluorescent dimming, strength weakened in the UV-B are lower than the control group (CK) during processing. At the same time we found that PCNAs proteins were mainly located in the two poles of cell at the stage of division in control and this phenomenon was more obvious under UV-B condition (Addition) (Figure 5). It shows that PCNA may be involved in the chromosomes separation and the dynamic distribution of PCNA may have relationship with “partition-bundle division”.

\section{Discussion}

We all know proteins play an important role in various physiological processes. They are not only the important components of organisms, but also as biological enzymes in catalytic reaction. Due to the maximum absorption wavelength of proteins is just UV-B radiation wavelength range, the protein itself will be affected by UV-B radiation [26]. It is essential to study the response of proteins to UV-B stress. This information may help spark ideas for protecting plants from enhanced UV-B radiation

He-Ne laser impact on plant growth has received increasing attention, which has caused some preliminary studies. Studies have shown that Laser irradiation can change the enzymatic conformation, making activity of enzymes increased. But, low dose of laser irradiation can promote plant growth and development, physiological metabolism [5]. Treatment with He-Ne laser helps accelerate seedling growth and development [6].

Recently, there are some studies of PCNA protein in plant resistance. This experiment based on different groups of PCNA proteins, then, extraction, identification. Illustrates the UV-B radiation reduces PCNA protein content, and after He-Ne laser processing its content will be restored. At the same time for each group of RT-PCR analysis comparison. Further to each set of chromosomes and PCNA protein in the FITC Mark after strong fluorescence degree analysis and comparison. We observed mitosis occurs abnormal and chromosome aberration. The PCNA was marked fluorescent dimming, strength weakened in the UV-B are lower than the control group (CK) during processing. Show that PCNA may be involved in the separation of chromosomes and the dynamic distribution of PCNA may have relationship with “partition-bundle division”.

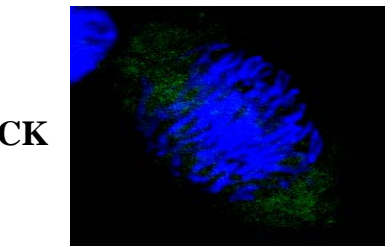

A

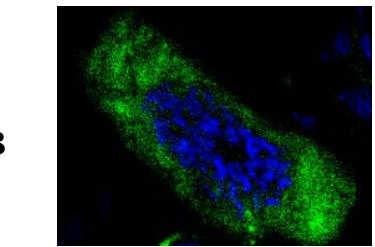

E

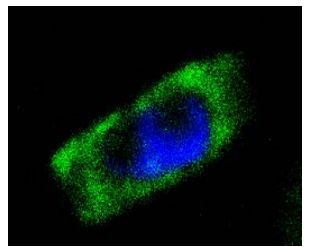

B

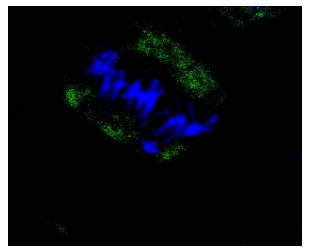

F

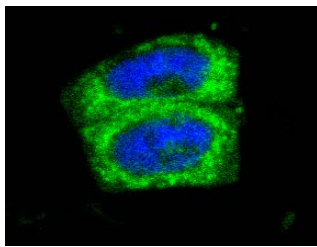

C

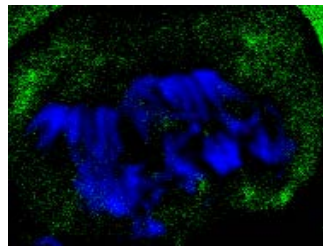

G

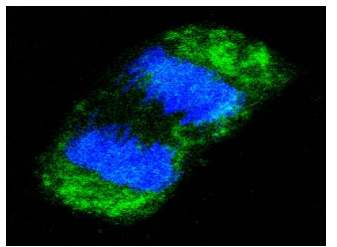

D

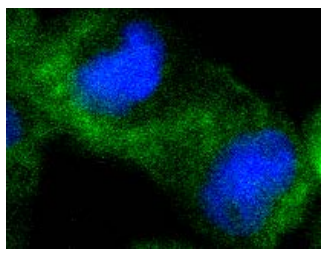

H

Figure 5. The subcellular localization of PCNA proteins at the stage of division in root-tip cells. PCNA proteins were stained in green and chromosomes in blue. (A)-(D) were control group (CK) obtained by DAPI and FITC fluorescence, in (D)-(H). were elevated UV-B-damaging radiation (B) obtained by DAPI and FITC fluorescence. 


\section{Conclusion}

In this article, we explored the effects of continuous wave He-Ne laser irradiation on PCNAs damage repair function of wheat seedlings exposed to enhanced UV-B radiation at the early growth stages. Altogether, our provide data evidenced by western blot and RT-PCR observation of PCNA protein and gene expression changed in wheat Seedlings. The results of LCSM showed that chromosomes were changed with PCNAs. At the same time, it preliminarily discussed some connections between the changes of chromosome and PCNAs under the enhanced UV-B, He-Ne laser irradiation. But it remained further researches about how PCNA protein regulated mitosis, and their quantitative relationship.

\section{Acknowledgements}

The work was supported by the National Nature Science Foundation of China (No. 30671061) and The Natural Science of Shanxi Province (No. 20081101, 2014011028-5).

\section{References}

[1] Zhao, J., Chen, H.Z. and Han, R. (2014) The Effects of He-Ne Laser and Enhanced Ultra Violet-B Radiation on PCNA in Wheat Seedlings. VEGETOS, 27, 17-24.

[2] Jansen, M.A.K., Gaba, V. and Greenberg, B.M. (1998) Higher Plants and UV-B Radiation: Balancing Damage, Repair and Acclimation. Trends in Plant Science, 3, 131-135. http://dx.doi.org/10.1016/S1360-1385(98)01215-1

[3] Jenkins, G.I. (2009) Signal Transduction in Responses to UV-B Radiation. Annual Review of Plant Biology, 60, 407431. http://dx.doi.org/10.1146/annurev.arplant.59.032607.092953

[4] Chen, H.Z. and Han, R. (2014) He-Ne Laser Treatment Improves the Photosynthetic Efficiency of Wheat Exposed to Enhanced UV-B Radiation. Laser Physics, 24, 10-17. http://dx.doi.org/10.1088/1054-660X/24/10/105602

[5] Han, R. (2002) Effects of the Enhanced UV-B Radiation on the Body Cell Mitosis of the Wheat. Ph.D. Dissertation, College of Life Sciences, Northwest University, Xi'an.

[6] Chen, Y.-P., Yue, M. and Wang, X.-L. (2005) Influence of He-Ne Laser Irradiation on Seeds Thermodynamic Parameters and Seedlings Growth of Isatis indogotica. Plant Science, 168, 601-606. http://dx.doi.org/10.1016/j.plantsci.2004.09.005

[7] Qi, Z., Yue, M., Han, R. and Wang, X.-L. (2002) The Damage Repair Role of He-Ne Laser on Plants Exposed to Different Intensities of Ultraviolet-B Radiation. Photochemistry and Photobiology, 75, 680-686. http://dx.doi.org/10.1562/0031-8655(2002)075<0680:TDRROH>2.0.CO;2

[8] Qi, Z., Yue, M. and Wang, X.-L. (2000) Laser Pretreatment Protects Cells of Broad Bean from UV-B Radiation Damage. Photochemistry and Photobiology, 59, 33-37. http://dx.doi.org/10.1016/S1011-1344(00)00131-7

[9] Qiu, Z.-B., Li, J.-T. and Yue, M. (2010) The Damage Repair Role of He-Ne Laser on Wheat Exposed to Osmotic Stress. Canadian Journal of Plant Science, 90, 691-698. http://dx.doi.org/10.4141/CJPS09118

[10] Pan, M., Kelman, L.M. and Kelman, Z. (2011) The Archaeal PCNA Proteins. Biochemical Society Transactions, 39, 2024. http://dx.doi.org/10.1042/bst0390020

[11] Kawai, A., Higuchi, S., Tsunoda, M., Nakamura, K.T. and Miyamoto, S. (2009) Purification, Crystallization and Preliminary X-Ray Analysis of the PCNA2-PCNA3 Complex from Sulfolobus tokodaiistrain 7. Structural Biology and Crystallization Communications, 65, 1282-1284. http://dx.doi.org/10.1107/S1744309109044479

[12] Strzalka, W. and Aggarwal, C. (2013) Proliferating Cell Nuclear Antigen 1 and 2 Possibly form Homo- and HeteroTrimeric Complexes in the Plant Cell. Plant Signaling and Behavior, 8, Article ID: e24837. http://dx.doi.org/10.4161/psb.24837

[13] Dore, A.S., Kilkenny, M.L., Jones, S.A., Oliver, A.W., Roe, S.M., Bell, S.D. and Pearl, L.H. (2006) Structure of an Archaeal PCNA1-PCNA2-FEN1 Complex: Elucidating PCNA Subunit and Client Enzyme Specificity. Nucleic Acids Research, 34, 4515-4526. http://dx.doi.org/10.1093/nar/gkl623

[14] Almendral, J.M., Huebsch, D., Blundell, P.A., Macdonald, B.H. and Bravo, R. (1987) Cloning and Sequence of the Human Nuclear Protein Cyclin: Homology with DNA-Binding Proteins. Proceedings of the National Academy of Sciences of the United States of America, 84, 1575-1579. http://dx.doi.org/10.1073/pnas.84.6.1575

[15] Yamaguchi, M., Hayashi, Y., Hirose, F., Matsuoka, S., Moriuchi, T., Shiroishi, T., et al. (1991) Molecular Cloning and Structural Analysis of Mouse Gene and Pseudogenes for Proliferating Cell Nuclear Antigen. Nucleic Acids Research, 19, 2403-2410. http://dx.doi.org/10.1093/nar/19.9.2403

[16] Bauer, G.A. and Burgers, P.M. (1990) Molecular Cloning, Structure and Expression of the Yeast Proliferating Cell 
Nuclear Antigen Gene. Nucleic Acids Research, 18, 261-265. http://dx.doi.org/10.1093/nar/18.2.261

[17] Suzuka, I., Daidoji, H., Matsuoka, M., Kadowaki, K., Takasaki, Y., Nakane, P.K., et al. (1989) Gene for ProliferatingCell Nuclear Antigen (DNA Polymerase Delta Auxiliary Protein) Is Present in both Mammalian and Higher Plant Genomes. Proceedings of the National Academy of Sciences of the United States of America, 86, 3189-3193. http://dx.doi.org/10.1073/pnas.86.9.3189

[18] Strzalka, W. and Ziemienowicz, A. (2007) Molecular Cloning of Phaseolus vulgarisc DNA Encoding Proliferating Cell Nuclear Antigen. Journal of Plant Physiology, 164, 209-213. http://dx.doi.org/10.1016/j.jplph.2006.04.009

[19] Strzalka, W., Kaczmarek, A., Naganowska, B. and Ziemienowicz, A. (2010) Identification and Functional Analysis of PCNA1 and PCNA-Like1 Genes of Phaseolus coccineus. Journal of Experimental Botany, 61, 873-888. http://dx.doi.org/10.1093/jxb/erp354

[20] Yamaguchi, M., Nishida, Y., Moriuchi, T., Hirose, F., Hui, C.C., Suzuki, Y., et al. (1990) Drosophila Proliferating Cell Nuclear Antigen (Cyclin) Gene: Structure, Expression during Development, and Specific Binding of Homeodomain Proteins to Its 5'-Flanking Region. Molecular and Cellular Biology, 10, 872-879.

[21] Ruike, T., Takeuchi, R., Takata, K., Oshige, M., Kasai, N., Shimanouchi, K., et al. (2006) Characterization of a Second Proliferating Cell Nuclear Antigen (PCNA2) from Drosophila melanogaster. FEBS Journal, 273, 5062-5073. http://dx.doi.org/10.1111/j.1742-4658.2006.05504.x

[22] Arabidopsis Genome Initiative (2000) Analysis of the Genome Sequence of the Flowering Plant Arabidopsis thaliana. Nature, 408, 796-815.

[23] López, I., Khan, S., Vázquez-Ramos, J. and Hussey, P.J. (1995) Molecular Cloning of a Maize cDNA Clone Encoding a Putative Proliferating Cell Nuclear Antigen. Biochimica et Biophysica Acta, 1260, 119-121. http://dx.doi.org/10.1016/0167-4781(94)00192-6

[24] López, I., Khan, S., Vázquez, J. and Hussey, P.J. (1997) The Proliferating Cell Nuclear Antigen (PCNA) Gene Family in Zea maysis Composed of Two Members That Have Similar Expression Programmes. Biochimica et Biophysica Acta, 1353, 1-6. http://dx.doi.org/10.1016/S0167-4781(97)00072-9

[25] Chen, H.Z. and Han, R. (2015) F-Actin Participates in the Process of the Partition-Bundle Division. Russian Journal of Plant Physiology, 62, 187-194. http://dx.doi.org/10.1134/S102144371502003X

[26] Barbato, R., Frizzo, A., Friso, G., Rigoni, F. and Giacometti, G.M. (1995) Degradation of the D1 Protein of Photosystem-II Reaction Centre by Ultraviolet-B Radiation Requires the Presence of Functional Manganese on the Donor Side. European Journal of Biochemistry, 227, 723-729. http://dx.doi.org/10.1111/j.1432-1033.1995.tb20194.x 